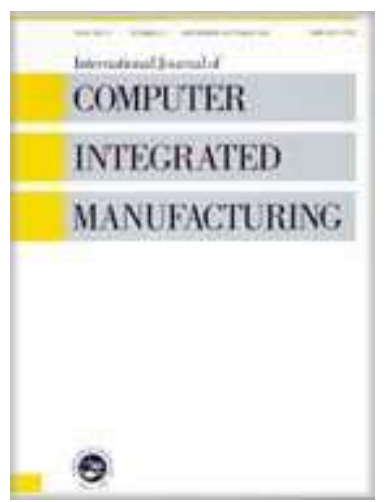

\title{
FAIM2007 Special Issue: The search for the optimal number of kanbans in unstable assembly-tree layout systems under intensive loading conditions
}

\begin{tabular}{|r|l|}
\hline Journal: & International Journal of Computer Integrated Manufacturing \\
\hline Manuscript ID: & TCIM-2007-IJCIM-0150.R1 \\
\hline Manuscript Type: & Special Issue Paper \\
\hline Date Submitted by the & 22-Apr-2008 \\
\hline Complete List of Authors: & $\begin{array}{l}\text { Iannone, Raffaele; University of Salerno, Dept. of Mechanical } \\
\text { Engineering } \\
\text { Miranda, Salvatore; University of Salerno, Dept. of Mechanical } \\
\text { Engineering } \\
\text { Riemma, Stefano; University of Salerno, Dept. of Mechanical } \\
\text { Engineering }\end{array}$ \\
\hline Keywords (user): & JIT, KANBAN \\
\hline Keywords: & \\
\hline
\end{tabular}

\section{S) ScholaroNE \\ Manuscript Central}




\title{
The search for the optimal number of kanbans in unstable assembly-tree layout systems under intensive loading conditions
}

\author{
Raffaele IANNONE*, Salvatore MIRANDA, Stefano RIEMMA \\ Department of Mechanical Engineering \\ University of Salerno \\ Fisciano, SA, 84084, Italy
}

\begin{abstract}
The JIT system and its operational techniques have shown noticeable advantages when applied in an ideal factory. The steadiness of demand and production times and the reduction of setup times represent the key factor necessary in order to correctly execute JIT. Ideal environments are designed to work with smooth and stable demand patterns, constant and balanced processing times, small lot sizes and without scraps and reworks. However, these conditions are difficult to realize in real productive systems. In these contexts, the increase of operational costs, due to the growth of inventories, necessary to match demand, often causes the failure of many JIT implementations. For these reasons, during the past years researchers have been investigating the issues related to JIT implementation in unsteady productive organizations. In this area, the kanban system, responsible for the exact propagation of information and for inventory control, is the most widely researched control mechanism. Literature proposes various kanban systems; in all cases the determination of the number of kanbans depends both on the management method chosen at each stage of the process as well as on the fluctuation of operative variables. This study deals with the problem of choosing the optimal number of kanbans in a multistage productive environment organized in an assembly-tree layout. In particular, this paper proposes a heuristic procedure to determine the number of kanbans and compares it with the traditional methods applied in manufacturing contexts.
\end{abstract}

Keywords: Just in Time system; Kanban; Simulation.

\section{Introduction}

The design of a production system able to implement a Just-in Time (JIT) control mechanism represents a challenge at all levels of business management. The global benefits of a JIT implementation necessitate specific improvements in the different areas of JIT philosophy: a series of macroscopic (development and implementation) and microscopic (specific improvements) phases lead to a successful implementation. The latter include all microtunings of the system to be developed in the long-term after JIT implementation (Gelinas, 1999). Each phase of the implementation should consider two essential aspects: the costs of each activity and the time necessary to realize it. In 2003, Yasin et al. carried out a survey of 130 manufacturers and 61 service companies on the reasons that lead companies to realize a JIT implementation. The results were: the reduction of material inventory (100\%), the increase in operations efficiency $(80 \%)$, the possibility of gaining a competitive advantage $(68 \%)$, the necessity to increase the level of service offered to customers $(64 \%)$, the reduction of the space required for raw materials $(60 \%)$, the improvement of product/service quality (48\%). The attainment of these goals requires small-lot production, stable scheduling, high-quality processes, reduction in setup times, preventive maintenance and a flexible layout. According to the study conducted by Fullerton and McWatters (2001), the most important advantages that a JIT implementation guarantees are: reduction of raw materials inventory and "work in process" (WIP) (81\%) and reduction of queue times (75\%). Fullerton et al. (2003), basing their research on 253 US manufacturing firms, studied the relationship existing between the degree of implementation of JIT systems and the deriving profit. Although many authors assert that the full advantages of a JIT implementation cannot be attained until all its elements are applied (White and Prybutok, 2001), the survey conducted by Fullerton et al. demonstrates that companies which had reached maximum JIT development did not obtain the maximum in terms of profit. This indicates that there is a level of JIT implementation, obviously depending on the type of company, above which is

\footnotetext{
*Corresponding author: Tel.: (+39) 089-964004; Fax: (+39) 089-964037; E-mail: riannone@unisa.it
} 
not advantageous to go.. Therefore, the search for the optimal stage, in terms of quality of products, reduction of setup time, etc., is a process which may not necessarily produce an increase in business performance.

The search for methods able to achieve the best results with minimal economic effort, has led many researchers, during the past years, to study the optimization of the different aspects characterizing JIT. In particular, Akturk and Erhun (1999), analyzing the research into these problems, broke down the factors which characterize them. In particular they identified the main characteristics of productive systems (i.e. layout, time period, product structure, number of stages, capacity constraints), the type of kanban system (Single-card or dual-card kanban), the decisional variables (number of kanbans, interval between orders, size of security stocks, size of containers) and the assumptions made (Stochastic variables, system reliability, etc.) in all the studies analyzed. Among the techniques proposed for stock level control and production coordination, one of the most studied is the kanban. According to a study conducted by White and Prybutok (2001), the use of the kanban system in US companies implementing JIT is almost $70 \%$. Studies propose kanban systems which differ in type (e.g.: single card, dual card, signal, etc.) (Celano et al., 2004) and in management method (e.g.: instantaneous, periodic review, simultaneous, independent, etc.) (McMullen and Frazier, 2000; Jin and Wu, 2002). The choice of the best kanban system depends on the specific context in which it has to be implemented. The dimensioning of the number of kanbans - known as Kanban Allocation Problem (KAP) - and the components for each container depends on the method chosen at each stage of the process as well as on the fluctuation of the operating variables (Xiaobo et al., 1999; Xiaobo and Ohno, 1997). For this reason, several different methods of studying KAP efficiently have been proposed in literature (Drexl and Matthieben, 2006; McMullen, 2001; Khan and Sarker, 2002). Particular attention has been dedicated to the mechanisms, based on the instantaneous production rate, for dynamically recalculating the number of kanbans (Drexl and Kimms, 2001; Kis, 2004; Kurashige et al. 1999). One of the most common tools used to study kanban problems in unstable environments is simulation; this is because it is able to take into consideration, in a relatively simple way, both process variability and production constraints (e.g.: transportation system, machines availability, etc.) (Akturk and Erhun,1999; Xiaobo et al., 1999; Kis, 2004; Palaniswami and Krishnamoorthy, 1996; Baykoc and Erol, 1998).

Nevertheless, most of the exact or approximate methods proposed and compared in literature are limited to applications in simplified production systems, while the problem of their validity in more complex and changeable scenarios is rarely considered in quantitative terms (Alabas et al., 2000; Alabas et al., 2002).

This paper aims to define a procedure, supported by optimization through simulation, to determine the optimal number of kanban in order to minimize inventory, setup, transportation and backlog costs in the first stage of a JIT implementation. This method uses the dual-card kanban and the "time periodic" technique of kanban management. The procedure has been verified by comparing it, through a simulation model, with the traditional criteria of kanban calculation (EPQ, EPQ with overlapping, multi-product EPQ, etc) and with other models of kanban management, such as the "Quantity Periodic" model and the "instantaneous" model.

\section{Problem Formulation}

The formal structure of the considered optimization problem will be synthetically described in the next paragraphs. Its main elements are the set of $m$ manufacturing cells $M A=\left(M A_{i}\right)=\left(M A_{1}, M A_{2}, \ldots, M A_{m}\right)$ and the set of $n$ produced items $P=\left(P_{j}\right)=\left(P_{1}, P_{2}, \ldots, P_{n}\right)$. The cells $M A$ are characterized by a total productive capacity $C=\left(C_{i}\right)=\left(C_{1}, C_{2}, \ldots, C_{m}\right)$. The scenario provides for the possibility that each item $P_{j}$ can be produced by a single cell. The hourly quantity of each item necessary to satisfy total demand is shown in the $D$ vector, defined as $D=\left(D_{j}\right)=\left(D_{1}, D_{2}, \ldots, D_{n}\right)$, in which $D_{j}$ is the hourly quantity request for item $P_{j}$.

The relation between $P_{j}$ and $M A_{j}$, which produce it, are shown in the $T(m, n)$ matrix, defined as:

$$
T=\left[t_{i j}\right]=\left[\begin{array}{cccc}
t_{11} & t_{12} & \ldots & t_{1 n} \\
t_{21} & t_{22} & \ldots & t_{2 n} \\
\ldots & \ldots & \ldots & \ldots \\
t_{m 1} & t_{m 2} & \ldots & t_{m n}
\end{array}\right] \quad i \in\{1, \ldots, m\} \text { and } j \in\{1, \ldots, n\}
$$

in which the time $t_{i j}$ represents the processing time of $P_{j}$ performed by $M A_{i}$.

The load $L_{i j}$ is the productive load generated by the production of $P_{j}$ on $M A_{i}$; it is given by the formula: 


$$
L_{i j}=\frac{D_{j} \cdot t_{i j}+t s_{i j} \cdot n s_{i j}}{C_{i}}
$$

where $t s_{i j}$ is the setup time of $P_{j}$ on $M A_{i}$ and $n s_{i j}$ is the total number of setups of $P_{j}$ on $M A_{i}$;

The "theoretical" saturation of $M A_{i}$ is obtainable by this formula:

$$
S_{i}=\sum_{j=1}^{n} L_{i j}
$$

$S_{i}$ indicates the percentage of $M A_{i}$ 's productive capacity assigned to perform all the productions of the cell. Depending on $D$ vector and $T$ matrix, $S_{i}$ can be less, equal or higher than the unit. This means, respectively, that the capacity is underutilized, fully utilized or not sufficient to guarantee that production plans are respected.

In order to understand the objective of this study, the problem that has to be analyzed must be formally identified. To do this, we define the kanban system that concurs to manage the productive flow of the JIT scenario and the Kanban Allocation Problem (KAP) that has to be studied. Its elements are:

$k p_{j}$ number of production kanbans for $P_{j}$ and $K_{p}=\sum_{j=1}^{n} k p_{j}$ total number of production kanbans in the system;

$k w_{j}$ number of withdrawal kanbans for $P_{j}$ and $K_{w}=\sum_{j=1}^{n} k w_{j}$ total number of withdrawal kanbans in the system;

$c_{j}$ size of the container relative to $P_{j}$;

$\Gamma_{h}=\left(k p_{1}, k p_{2}, \ldots, k p_{n}\right)$ a possible production kanban allocation for the $n$ items;

$\Psi_{l}=\left(k w_{1}, k w_{2}, \ldots, k w_{n}\right)$ a possible withdrawal kanban allocation for the $n$ items;

$\Phi_{s}=\left(c_{1}, c_{2}, \ldots, c_{n}\right)$ a possible containers size allocation for the $n$ items;

$a_{i}=a_{i}\left(\Gamma_{h}, \Phi_{s}\right)=\sum_{P_{j} \in M A_{i}}\left[t s_{i j} \cdot n s_{i j}\right]$ the total setup time of $M A_{i}$ cell corresponding to the $\Gamma_{\mathrm{h}}$ and $\Phi_{s}$ allocations.

The kanban allocation influences the total setup time as a consequence of the necessity to make, according to this amount, a greater or smaller number of setups;

$g_{j}$ mean stock dimension of $P_{j}$ item corresponding to the $\Gamma_{\mathrm{h}}$ and $\Psi_{l}$ allocations and to the container size;

$t_{j}$ total transportation time of $P_{j}$ item corresponding to the $\Gamma_{\mathrm{h}}$ and $\Psi_{l}$ allocations and to the container size;

$p_{j}$ mean production rate per time unit of $P_{j}$ item;

$c s_{i}$ setup costs per time unit of $M A_{i}$ cell;

$c h_{j}$ inventory costs per unit of $P_{j}$ item;

$c t_{j}$ transportation costs per time unit of $P_{j}$ item;

$c b_{j}$ backlog costs per unit of $P_{j}$ item not delivered on time;

$R$ set of rules for the management of the production kanbans processing (reorder point periodic management, fixed time periodic management, instantaneous management), $\forall r \in R$ it is possible to define the Kanban Allocation Problem (KAP) proposed in this study:

(KAP-1)

$$
\sum_{i=1}^{m} a_{i} \cdot c s_{i}+\sum_{j=1}^{n} g_{j} \cdot c h_{j}+\sum_{j=1}^{n} t_{j} \cdot c t_{j}+\sum_{j=1}^{n}\left|D_{j}-p_{j}\right| \cdot c b_{j} \longrightarrow \underset{\Gamma_{h}, \Psi_{l}, \Phi_{s}}{\operatorname{Min}}
$$

The formulation aims to find the container size, the allocation of kanban and the management rule that concur to minimize the total inventory, setup, transportation and backlog costs of the entire system.

\section{Problem Analysis and Approach to solution}

The trend of the costs considered in this paper has been studied as a function of the number of kanbans and the dimension of the containers:

1. The total setup cost, once the dimensions of the containers have been established, assumes a decreasing trend according to the number of kanbans in the system (see Figure 1A). This depends on the necessity, 
with specific productive cadence, to carry out a high number of setups in the presence of a reduced number of kanban.

2. The stock dimension rises with the number of kanbans and with the dimension of the containers (see Figure 1B).

3. The transportation times, once the dimensions of containers have been established, decrease with the number of kanbans; this is caused by the faster rotation necessary to guarantee the needed productive cadence (see Figure 1C).

4. The trend of the service level based on the dimension of the container has been studied by Chan, (2001) and Savsar (1997). They assume the trend shown in Figure 1D. Indirect measures of the service level according to the dimension of the supplies have been also studied by Bonvik et al.(1997).

Figure 1 - Costs tendency based on the kanban number

The trend of the costs shown in Figure 1 is referred to the mean values of both costs and number of kanbans present in the system. It is clear, when the specific problem is analysed in detail, that the total number of kanbans is a reliable index only at inventory levels. On the contrary, it is of little meaning if other aspects are considered, especially if the production environment is unstable. In the presence of instability in the production process and when a manufacturing cell depends on another (which typically happens in assembly-tree and multi-stage productive environments), the trend of costs is not easily expressible with mathematical formulae. In particular, the choice of the number of kanbans in each cell and for each product determines different results in terms of cost and performance of the system, even if the total number of kanbans remains the same.

Each cell can be represented as shown in Figure 2. The cells can produce more than one item (output of the cell) by "consuming" various types of raw materials from other cells. The cycle of the production kanbans is completed within the cell, while the withdrawal kanbans complete their cycle between two adjacent stages. The existing connections between the cells are not fixed, but vary according to the finished product.

Figure 2 - Flow of kanbans and containers in a single stage

In these conditions it is evident that even with the same total number of kanbans, the performances, in terms of transportation times, levels of service and setup times, depend on the specific allocation of the kanban in each productive cell. These performance indexes are also influenced by the kanban management rule adopted for each single cell. In these conditions, this paper intends to define a procedure for the determination of the optimal allocation of dual-card kanban and the dimension of the containers in a multi-item and multi-stage productive environment organized in an "assembly-tree" layout, with the purpose of reducing the total amount of setup, inventory, transportation and backlog costs of the entire process. This procedure uses analytical techniques, in order to identify the macroscopic domain of surveying, and simulation techniques, in order to explore the correct allocation of the kanbans in detail.

\section{The heuristic procedure}

The number of production and withdrawal kanbans and the size of containers for each item in the system, using the "time periodic" management rule of production kanbans, are defined through the calculation procedure. The use of the simulator allows the effect of aleatory variables such as: run times, setup times, transportation times, synchronization time, etc., to be included in the calculation and therefore in the determination of the costs The procedure, characterized by an exploratory technique for the determination of the aforesaid operative parameters, makes use of known calculation techniques in order to limit the range of possible solutions. These techniques concur to reduce the number of runs necessary to obtain the optimal solution. The procedure is based on the following steps:

step 1. Determination of the Economic Production Quantity $(E P Q)$. The total inventory and setup cost for each $P_{j}$ item produced in the $M A_{i}$ cell and contemporarily consumed by the subsequent cells is minimised by EPQ. The range of possible solutions in a more limited interval of the total costs curve is restricted by this step. The EPQ can be calculated with the formula:

$$
E P Q_{j}=\sqrt{\frac{2 \cdot c s_{i} \cdot d_{j}}{c h_{j} \cdot\left(1-d_{j} / p_{j}\right)}}
$$

where $d_{j}$ is the mean rate of consumption per unit of time of $P_{j}$ item. 
step 2. Determination of the economic cycle of production kanban in $M A_{i}$ cell $\left(T_{j}\right)$. The determination of the economic cycle of production can be executed with the formula:

$$
T_{j}=E P Q_{j} / d_{j}
$$

The economic cycle of production $T_{j}$ is calculated (and rounded up) for each item. This interval may be different for each item produced in the same cell, but, in order to guarantee maximum service level and, at the same time, minimize the setup costs, the same interval for all items in the cell should be fixed. In the proposed procedure this interval is obtained (in step 5) through simulation. This approach assumes, as a range of possible values, the interval between the minimum and the maximum of the values calculated in the same cell.

step 3. Determination of production kanban. The number of production kanbans can be obtained through the formula proposed by Monden (1983):

$$
k p_{j}=\frac{d_{j} \cdot\left(T_{j}+t_{i j}+\alpha_{j}\right)}{c_{j}}
$$

Where $\alpha_{j}$ is the safety period. The container size $c_{j}$ is initially settled at the minimum value imposed by the bill of material.

step 4. Determination of withdrawal kanban. The number of withdrawal kanbans is based on the distance between production cells and item consumption cells. Once the distances and times to cover them have been calculated, the number of withdrawal kanbans may be calculated with the following formula:

$$
k w_{j}=\frac{d_{p} \cdot\left(T t_{j}+T w_{j}+\beta_{j}\right)}{c_{j}}
$$

Where: $d_{p}$ is the mean rate of parent item consumption per time unit $(\mathrm{j} \neq \mathrm{p}) ; T t_{j}$ is the transportation time for $P_{j}$ item; $T w_{j}$ is the waiting time to pick up all kanbans of $P_{j}$ item and $\beta_{j}$ is the safety period.

step 5. Simulation. Once the range of values for each production cycle and the number of production kanbans are defined, simulation allows the optimal values within that range to be determined. The optimization routine entails the execution of a run for each defined configuration; the comparison between the different runs determines the best scenario.

step 6. Optimization of container size._It is possible to calculate the container size at the end of the optimization | cycle. The container size could be increased, in multiples of the imposed minimum dimension, until the number of withdrawal kanbans is minimised. This increase allows transportation times to be reduced without excessively increasing inventory costs.

\section{Procedure verification}

The procedure for the determination of the optimal number of kanbans has been applied to a simulated scenario in order to verify its effectiveness. The experiment has been conducted in three phases:

1. Time Periodic analysis: allows the comparison of the results of the procedure with those obtained by the application of traditional calculation methods in order to determine the number of kanbans;

2. Quantity Periodic analysis: allows the comparison of the results of the procedure by varying the method of kanban management;

3. Sensitivity analysis: investigates the influence of the variations in the assembly sequence and the main operational parameters on the performance of the system.

\subsection{Productive environment}

The production environment, used to verify the procedure, is made up of 6 productive cells organized in an "assembly tree" layout. It realizes 3 finished assembled products, each one characterized by a 3-level bill of material. The demand profile is leveled and constant. The transportation times are stochastic. Table 1 summarizes the main parameters of the system. The productive system has been dimensioned to realize 6 finished products of type 1,5 of 
type 2 and 3 of type 3 per time unit, with an estimated saturation of productive cells given by: $S=(0.92,0.78,0.98,0.97,0.89,0.89)$.

Table 1 - Production system parameters

The tests have been conducted to verify the effective location of the minimum point on the total cost curve using the proposed procedure for the determination of the number of kanbans. The calculation of the number of kanbans has been carried out, not only with the proposed method but also using the Monden technique [23], in which the hypotheses for the calculation of the economic production quantity have been varied. The calculation of the economic production quantity determines the number of kanban using the formula:

$$
k p_{j}=\frac{\overline{E P Q}_{j}+d_{j} \cdot \alpha_{j}}{c_{j}}
$$

The criteria adopted to calculate the $\overline{E P Q}_{j}$ are: (a) Economic Production Quantity $\left(\overline{E P Q}_{j}\right)$; (b) Economic Production Quantity with overlapping $\left(\overline{E P Q}_{j}\right.$ over); (c) Economic Production Quantity with multi-product $\left(\overline{E P Q}_{j}\right.$ var); (d) Economic Production Quantity with overlapping and multi- product ( $\overline{E P Q}_{j}$ var over). In order to simplify the comparison between the scenarios, the runs have been realized fixing the number of withdrawal kanbans $\Psi_{E P Q}=\left(k w_{1}, k w_{2}, \ldots, k w_{n}\right)$ and the size of containers $\Phi_{E P Q}=\left(c_{1}, c_{2}, \ldots, c_{n}\right)$.

\section{2. “Time Periodic” Analysis}

Table 2 shows the allocation of production kanban in every simulated scenario. The values $\mathrm{kp} 1, \mathrm{kp} 2, \mathrm{kp} 3 \mathrm{refer}$ respectively to $\mathrm{P} 1, \mathrm{P} 2, \mathrm{P} 3$ items that, in the productive scenario, have a number of production kanban equal to zero because they represent the 3 finished products. Figure 3a shows the comparison between the total costs obtained using the different methods of calculation. The tests marked with "Ottimix" belong to the optimizing procedure; as evident in the graph, "Ottimix 7" represents the best scenario.

Table 2 - Production kanban allocation for "Time Periodic" scenarios

\section{3. "Quantity Periodic" Analysis}

The "Quantity Periodic" scenario is characterized by the management of production kanban with "reorder points". In fact, the launch in production of the kanbans only happens when they reach a pre-determined level in the binder. Table 3 shows the allocation of production kanbans for the scenarios. This analysis has allowed the proposed method to be evaluated by varying the technique of management of the kanbans. Figure $3 \mathrm{~b}$ shows the results and compares them with the best configuration obtained through the heuristic procedure ("Ottimix 7").

Table 3 - Production kanban allocation for "Quantity Periodic" scenarios

Figure 3 - Comparison between total costs (€) for "Time Periodic" (a) and "Quantity Periodic" (b) scenarios

\subsection{Sensitivity analysis}

The sensitivity analysis has been conducted to estimate how the performances of the configurations vary according to (1) demand mix and (2) functioning parameters of the assembly line.

\subsubsection{Variation of the demand mix}

The variation has permitted the sensitivity of the method to the deviation from the optimal conditions to be studied. The experiment has been conducted by fixing the number of kanbans and varying the demand mix. Figure $4 \mathrm{a}$ shows the variation of the total costs that ranges between $-6,5 \%$ and $+12 \%$ when the mix passes from the optimal 
configuration $(6,5,3)\left(D_{1}=6, D_{2}=5\right.$ and $\left.D_{3}=3\right)$ to the configurations $(5,6,3),(5,5,4)$ and $(6,4,4)$. This deviation, evident in other performance indicators, was predictable because of the variation of the parameters that mainly influence the calculation of the number of kanbans. However, the deviations obtained by applying the same variations to the scenario built with the EPQ method (that obtained the best results), while maintaining nearly the same trend, presents a greater deviation in comparison to the previous ones (see Figure 4b).

\section{Figure 4_- Gap analysis of the mix of demand}

\subsubsection{Variation of the main functioning parameters}

The sensitivity analysis on the proposed model has also been carried out by considering the variations in the most characterising parameters of the scenario:

- $\quad$ The Interarrival Time (IT) of the orders;

- $\quad$ The Run Time (RT);

- The Setup Time (ST).

In particular the main values and the standard deviation of these three parameters have been varied and the results have been analysed in the three following scenarios:

1. The effect of the standard deviations of IT, RT and ST on the objective function, once the number of kanbans has been calculated;

2. The effect of the main values of IT, RT and ST on the objective function, once the number of kanbans has been calculated;

3. The effect of the main values of IT, RT and ST on the objective function, with the recalculation of the number of kanbans.

The objective function has been defined as the percentage difference of unitary production costs obtained by applying the formulas of Monden $\left(C_{u}\right)$ and by using the proposed procedure $\left(C^{\prime}{ }_{u}\right)$ :

$$
F_{o b j}=\Delta C_{u} \%=\frac{C_{u}-C_{u}^{\prime}}{C_{u}} \cdot 100
$$

Scenario 1. The aim of scenario 1 is to evaluate how the increase of variability influences the performance of the system. This scenario does not require the recalculation of the number of kanbans because in the procedure this number depends on the mean values of the parameters. The matrix of the chosen values of the factors and the result of the ANOVA conducted on the outcomes of the experiment are shown in Table 4 and Table 5 respectively.

The stability of the proposed solution when the dispersions of the analysed factors vary is evident from the ANOVA analysis. Some of the factors are not relevant and the unitary cost remains significantly lower than the outcomes of Monden's model (see Figure 5).

Table 4 - Matrix of factors for scenario 1

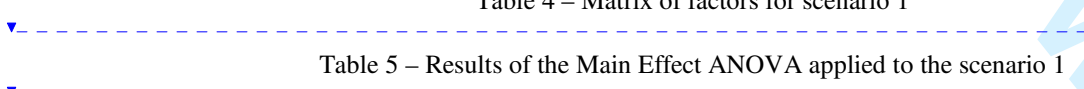

Figure 5 - Effect of factors in scenario 1

Scenario 2. Scenario 2, obtained by varying the mean values of the factors, has been tested in order to analyse the stability of the solution without recalculating the number of kanbans. The matrix of the values and the results of the ANOVA analysis are shown in Table 6 and Table 7.

The analysis has highlighted a significant effect of $\mu_{\mathrm{TT}}$ e $\mu_{\mathrm{RT}}$ on the objective function. In particular, Figure 6 shows that when IT decreases, the configuration determined through the procedure, compared to Monden's model, noticeably improves the performances of the system. On the contrary, when IT increases (and saturation of the system decreases) Monden's model is more effective because of its lower number of kanbans. The same effect is 
outlined by the graph relating to RT; when its mean values rise (and saturation increases) the procedure shows a considerable improvement in comparison to Monden's model.

Table 6 - Matrix of factors for scenario 2 and 3

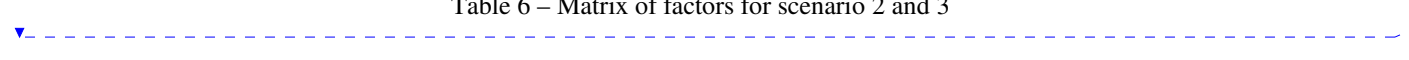

$\mathbf{v}$

Table 7 - Results of the Main Effect ANOVA applied to the scenario 2

Figure 6- Effect of factors in scenario 2

Scenario 3. This last scenario has been tested through the one-way ANOVA analysis in order to reduce the number of runs deriving from the iterative application of the simulation model necessary to find the optimal solution for each combination of factors. The matrix of factors is the same as that in scenario 2 (see Table 6). From the analysis of the results, shown in Table $\underline{8}$, it is clear that there is a significant influence of IT on the objective function. In particular (see Figure 7), when IT decreases (production rates and saturation increase) the procedure leads to better performances, while when production rates are reduced (higher IT) Monden's model seems to be slightly more effective. The variation on the mean values of RT and ST, on the contrary, does not evidence tangible effects on the unitary costs.

Table $\underline{8}-$ Results of the One-Way ANOVA applied to the scenario 3

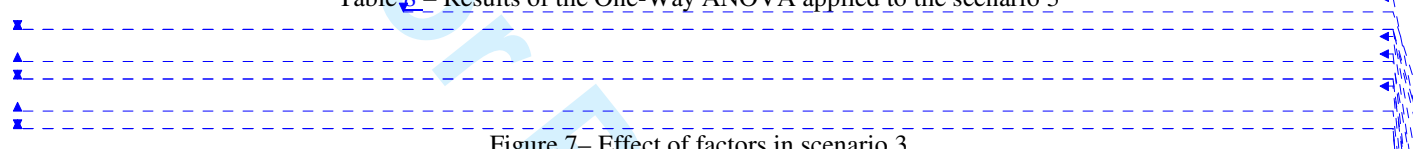

\section{Conclusions}

\section{Figure $7-\overline{E f f e c t}$ of factors in scenario 3}

The determination of the number of kanban necessary to correctly manage materials and information inside the JIT production process, is conditioned by operating variables that often have an aleatory nature. The traditional methods of choosing and allocating the optimal number of kanbans often do not consider these aleatory variables and so they can only be used effectively in stable conditions. For these reasons, this paper proposes a heuristic procedure to calculate the number of kanbans and the frequency of production order launches, that uses a simulation process of optimization supported by traditional methods, in order to determine the optimal number of kanbans.

The procedure has been compared, in virtual scenarios, with traditional techniques by varying the method of kanban management; it has shown interesting results in all the researched performance indicators. Finally, a sensitivity analysis has been conducted in order to verify the effectiveness of the procedure when the operative parameters mainly significant for the JIT scenario are changed.

The analysis has outlined a significant stability in the fluctuation of the main functioning parameters (scenario 1). These outcomes show the effectiveness of the results obtained in standard conditions and its stability even if there is a variation of standard deviations of the factors. Moreover, the experiments have emphasized a higher performance than the classical model proposed by Monden especially in high saturation conditions. This result has been confirmed both during the operating phase, without recalculating the number of kanbans (scenario 2), and during the phase of design of the JIT system, which requires the recalculation of kanbans (scenario 3).

\section{References}

Akturk M.S., Erhun F., An overview of design and operational issues of kanban systems, International Journal of Production Research Vol.37, No.17, pp. 3859-3881, 1999.

Alabas C., Altiparmak F., Dengiz B., The optimization of number of kanban with genetic algorithms, simulated annealing and tabu search, Proceedings of the IEEE Conference on Evolutionary Computation, vol. 1, pp 580-585, 2000

Alabas C., Altiparmak F., Dengiz B., A comparison of the performnce of artificail intelligence techiniques for optimizing the number of kanbans, Journal of Operational Research Society, 53, pp. 907-914, 2002;

Baykoc O.F., Erol S., Simulation modeling and analysis of a JIT production system, International Journal of Production Economics Vol.55, pp.203-212, 1998.

Bonvik A.M., Couch C.E., Gershwin S.B., A comparison of production-line control mechanisms, International Journal of

\begin{tabular}{|c|c|}
\hline \multicolumn{2}{|l|}{ Deleted: Effect } \\
\hline \multicolumn{2}{|c|}{$\begin{array}{l}\text { Formatted: FAIM Caption, Left, } \\
\text { Space Before: } 6 \text { pt, After: } 6 \text { pt, Keep } \\
\text { with next }\end{array}$} \\
\hline \multicolumn{2}{|c|}{ Formatted Table } \\
\hline \multicolumn{2}{|l|}{ Deleted: पा } \\
\hline \multicolumn{2}{|c|}{ Deleted: $\quad{ }^{2}$} \\
\hline \multicolumn{2}{|c|}{ Formatted: English (U.K.) } \\
\hline \multicolumn{2}{|l|}{ Deleted: 7} \\
\hline \multicolumn{2}{|l|}{ Deleted: 7} \\
\hline \multicolumn{2}{|c|}{ Deleted: Effect } \\
\hline \multicolumn{2}{|c|}{ Formatted: English (U.K.) } \\
\hline \multicolumn{2}{|c|}{$\begin{array}{l}\text { Formatted: Indent: First line: } 0 \mathrm{pt} \text {, } \\
\text { Line spacing: Exactly } 11 \mathrm{pt}\end{array}$} \\
\hline \multicolumn{2}{|c|}{ Formatted: English (U.K.) } \\
\hline \multicolumn{2}{|c|}{$\begin{array}{l}\text { Formatted: Font: } 10 \text { pt, English } \\
\text { (U.S.) }\end{array}$} \\
\hline \multicolumn{2}{|c|}{$\begin{array}{l}\text { Formatted: Indent: First line: } 0 \mathrm{pt} \text {, } \\
\text { Line spacing: Exactly } 11 \mathrm{pt}\end{array}$} \\
\hline \multicolumn{2}{|l|}{ Deleted: Effect } \\
\hline \multicolumn{2}{|c|}{$\begin{array}{l}\text { Formatted: Font: } 10 \text { pt, Not Bold, } \\
\text { English (U.S.) }\end{array}$} \\
\hline \multicolumn{2}{|c|}{$\begin{array}{l}\text { Formatted: Indent: First line: } 0 \mathrm{pt} \text {, } \\
\text { Line spacing: Exactly } 11 \mathrm{pt}\end{array}$} \\
\hline \multicolumn{2}{|c|}{$\begin{array}{l}\text { Formatted: Font: } 10 \mathrm{pt} \text {, English } \\
\text { (U.S.) }\end{array}$} \\
\hline \multicolumn{2}{|c|}{$\begin{array}{l}\text { Formatted: Indent: First line: } 0 \mathrm{pt} \text {, } \\
\text { Line spacing: Exactly } 11 \mathrm{pt}\end{array}$} \\
\hline \multicolumn{2}{|c|}{ Deleted: Effect } \\
\hline \multicolumn{2}{|c|}{ Formatted: English (U.K.) } \\
\hline \multicolumn{2}{|c|}{ Formatted: English (U.K.) } \\
\hline Deleted: $\mathbb{I}$ & \\
\hline
\end{tabular}


Production Research Vol.35, No.3, pp.789-804, 1997.

Celano G., Costa A., Fichera S., A comparative analysis of sequencing heuristic for solving the Toyota Goal Chasing problem, Robotics and Computer-Integrated Manufacturing Vol. 20, pp. 573-581, 2004.

Chan F.T.S., Effect of kanban size on just-in-time manufacturing systems, Journal of Material Processing Technology Vol.116, pp.146-160, 2001.

Drexl A., MatthieBen L., Algorithms for the car sequencing and level scheduling problem, Journal of Scheduling Vol.9, pp.153$176,2006$.

Drexl A., Kimms A., Sequencing JIT Mixed-Model assembly lines under station-load and part-usage constraints, Management Science Vol.47, No.3, pp.480-491, 2001.

Fullerton R.R., McWatters C.S., The production performance benefits from JIT implementation, Journal of Operations Management Vol.19, pp. 81-96, 2001.

Fullerton R.R., McWatters C.S., Fawson C., An examination of the relationships between JIT and financial performance, Journal of Operation Management Vol. 21, pp. 383-404, 2003.

Jin M., Wu D., A new heuristic method for mixed model assembly line balancing problem, Computers \& Industrial Engineering Vol. 44, pp. 159-169, 2002.

Khan L.R., Sarker R.A., An optimal batch size for a JIT manufacturing system, Computers \& Industrial Engineering Vol. 42, pp.127-136, 2002. [1] Gelinas R., The Just-in-Time implementation project, International Journal of Project Management Vol.17, No.3, pp. 171-179, 1999.

Kis T., On the complexity of the car sequencing problem, Operations Research Letters Vol.32, pp.331-335, 2004.

Kurashige K., Yoshinari Y., Miyazaki S., Kameyama Y., Sequencing method for products in consideration of assembly time, International Journal of Production Economics Vol.60-61, pp.565-573, 1999.

McMullen P.R., An ant colony optimization approach to addressing a JIT sequencing problem with multiple objectives, Artificial Intelligence in Engineering Vol.15, pp.309-317, 2001.

McMullen P.R., Frazier G.V., A simulated annealing approach to mixed-model sequencing with multiple objectives on a just-intime line, IIE Transactions Vol.32, pp. 679-686, 2000.

Monden Y., Toyota Production System. Practical approach to production management, 1983.

Savsar M., Simulation analysis of a pull-push system for an electronic assembly line, International Journal of Production Economics Vol.51, pp.205-214, 1997.

Smith K., Palaniswami M., Krishnamoorthy M., Traditional heuristic versus Hopfield neural network approaches to a car sequencing problem, European Journal of Operational Research Vol.93, pp.300-316, 1996.

White R.E., Prybutok V., The relationship between JIT practices and type of production system, Omega The International Journal of Management Science Vol.29, pp. 113-124, 2001.

Xiaobo Z., Ohno K., Algorithms for sequencing mixed model on an assembly line in a JIT production system, Computers \& Industrial Engineering Vol. 32, pp. 47-56, 1997.

Xiaobo Z., Zhou Z., Asres A., A note on Toyota's goal sequencing mixed models on an assembly line, Computers \& Industrial Engineering Vol. 36, pp. 57-65, 1999.

Yasin M.M., Small M.H., Wafa M.A., Organizational modifications to support JIT implementation in manufacturing and service operations, Omega The International Journal of Management Science Vol.31, pp. 213-226, 2003. 


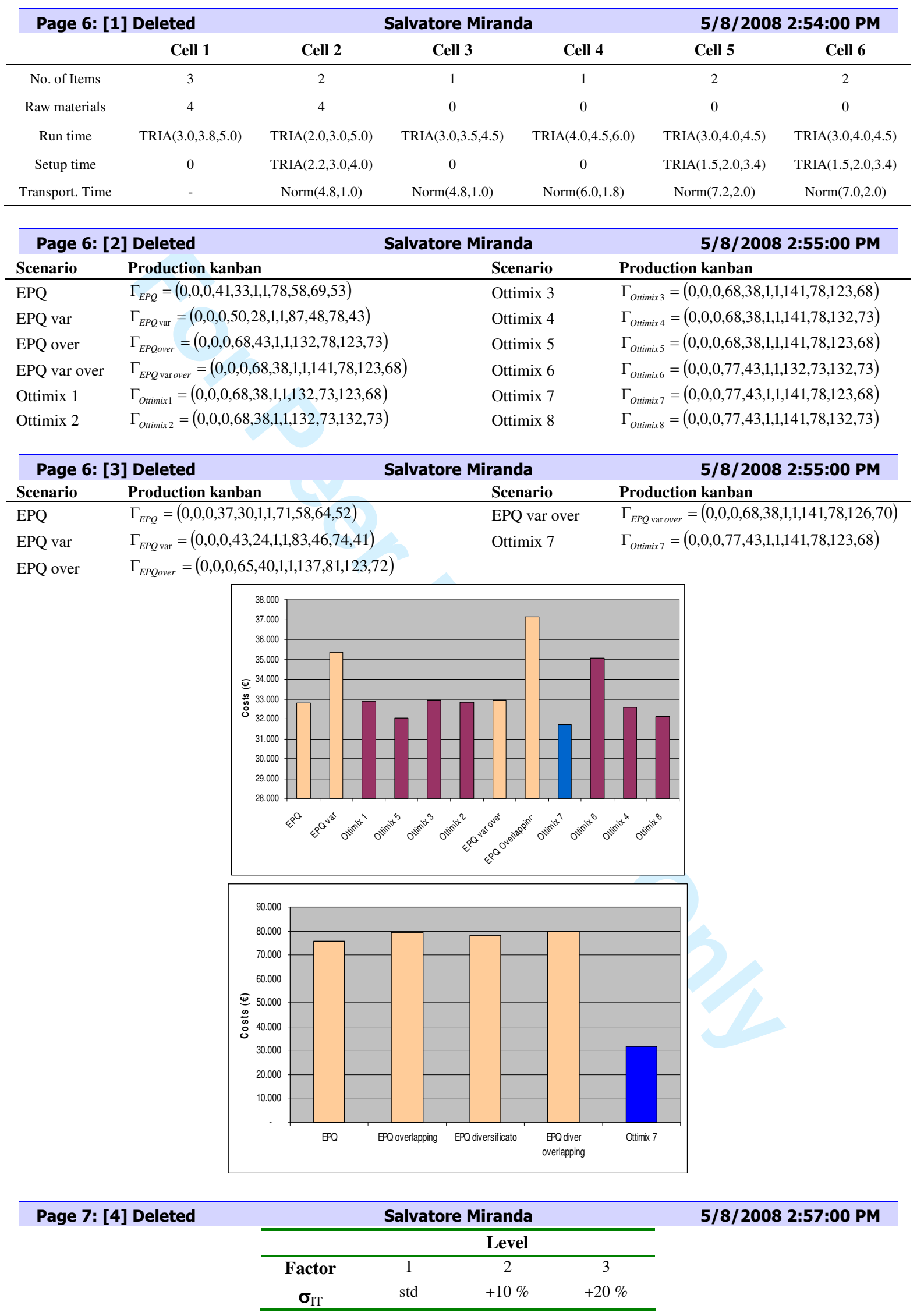




\begin{tabular}{llll}
\hline$\sigma_{\mathrm{RT}}$ & std & $+10 \%$ & $+20 \%$ \\
$\sigma_{\mathrm{ST}}$ & std & $+10 \%$ & $+20 \%$ \\
\hline
\end{tabular}

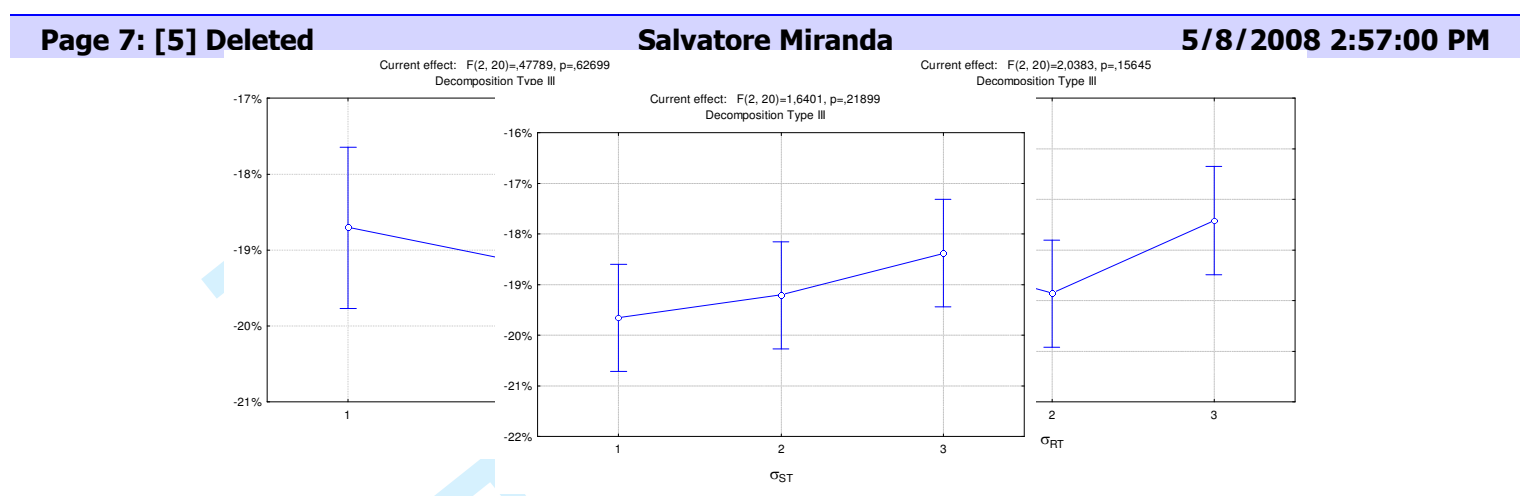

\begin{tabular}{lcccc}
\hline Page 8: [6] Deleted & \multicolumn{3}{c}{ Salvatore Miranda } & 5/8/2008 2:58:00 PM \\
\cline { 2 - 4 } & \multicolumn{4}{c}{ Level } \\
\cline { 2 - 4 } & Factor & 1 & 2 & 3 \\
$\mu_{\mathrm{IT}}$ & $-10 \%$ & std & $+10 \%$ \\
$\mu_{\mathrm{RT}}$ & $-10 \%$ & std & $+10 \%$ \\
$\mu_{\mathrm{ST}}$ & $-10 \%$ & std & $+10 \%$ \\
\hline
\end{tabular}

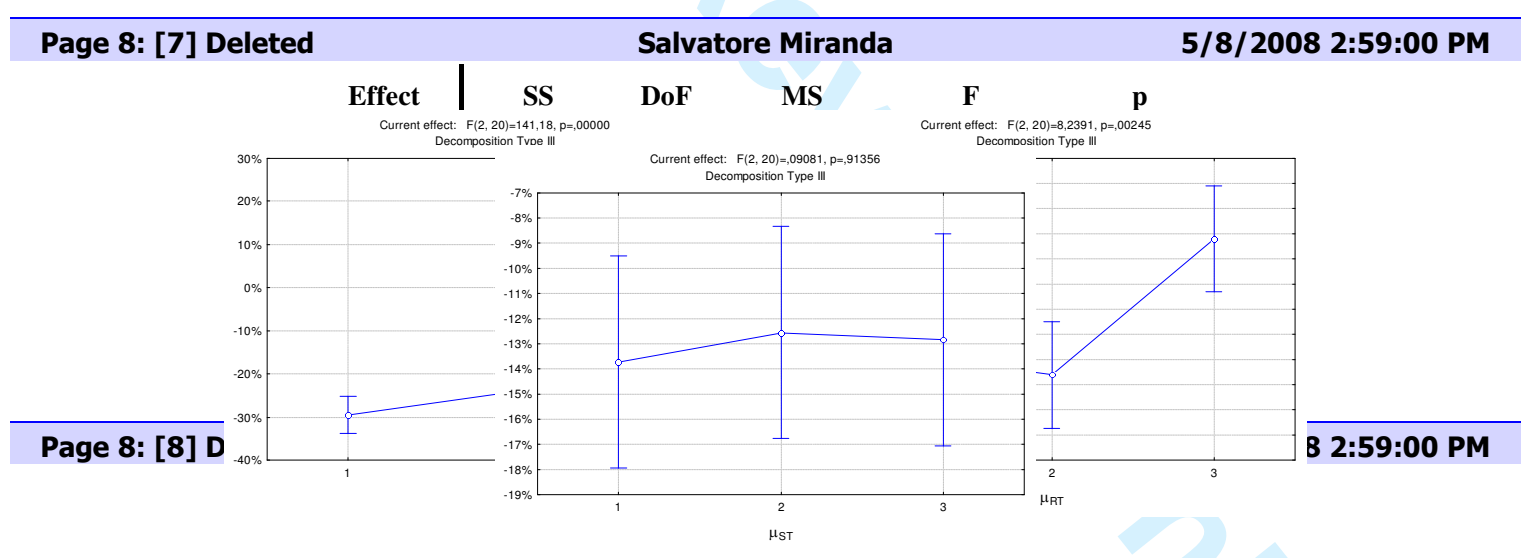

\begin{tabular}{|c|c|c|c|c|c|c|c|}
\hline \multirow[t]{2}{*}{ Page 8: [9] Deleted } & \multicolumn{6}{|c|}{ Salvatore Miranda } & \multirow[t]{2}{*}{ 5/8/2008 3:00:00 PM } \\
\hline & Effect & SS & DoF & MS & $\mathbf{F}$ & $\mathbf{p}$ & \\
\hline & $\mu_{\mathrm{IT}}$ & 0,853325 & 3 & 0,284442 & 17,60982 & 0,009068 & \\
\hline & Error & 0,064610 & 4 & 0,016152 & & & \\
\hline
\end{tabular}

\begin{tabular}{|c|c|c|c|c|c|c|c|}
\hline \multirow[t]{3}{*}{ Page 8: [10] Deleted } & \multicolumn{6}{|c|}{ Salvatore Miranda } & \multirow[t]{2}{*}{ 5/8/2008 3:01:00 PM } \\
\hline & $\begin{array}{r}E \\
\text { ffect }\end{array}$ & SS & ${ }_{o F}^{D}$ & MS & $\mathrm{F}$ & $\mathrm{p}$ & \\
\hline & $\mathrm{RT}^{\square}$ & $\begin{array}{c}0,62 \\
0536\end{array}$ & 3 & $\begin{array}{r}0,20 \\
6845\end{array}$ & $\begin{array}{c}2,78 \\
2064\end{array}$ & $\begin{array}{r}0,17 \\
4065\end{array}$ & \\
\hline
\end{tabular}

URL: http://mc.manuscriptcentral.com/tandf/tcim Email:ijcim@bath.ac.uk 
\begin{tabular}{c|lcc} 
E & \multicolumn{1}{c}{0,29} & & 0,07 \\
rror & 7399 & 4 & 4350
\end{tabular}

\begin{tabular}{|c|c|c|c|c|c|c|c|}
\hline \multirow[t]{2}{*}{ Page 8: [11] Deleted } & \multicolumn{6}{|c|}{ Salvatore Miranda } & \multirow[t]{2}{*}{ 5/8/2008 3:01:00 PM } \\
\hline & Effect & SS & DoF & MS & $\mathbf{F}$ & $\mathbf{p}$ & \\
\hline & $\mu_{\mathrm{ST}}$ & 0,683154 & 3 & 0,227718 & 3,879682 & 0,111641 & \\
\hline & Error & 0,234780 & 4 & 0,058695 & & & \\
\hline
\end{tabular}
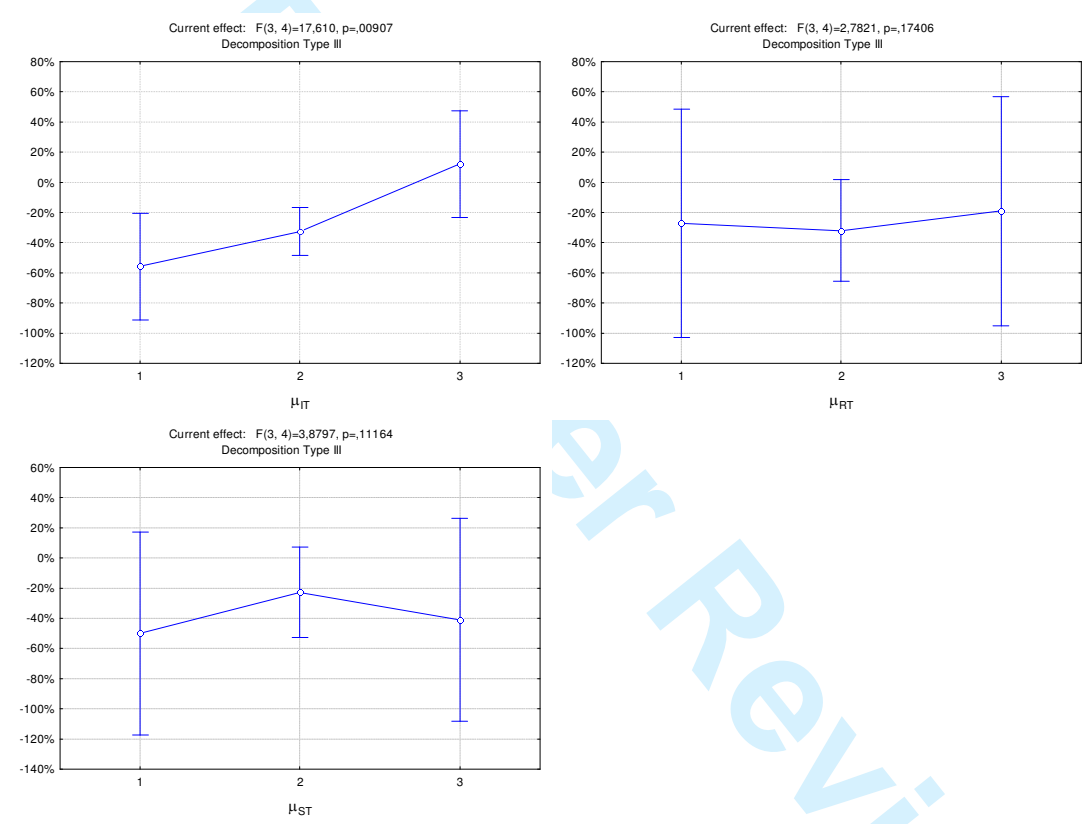

URL: http://mc.manuscriptcentral.com/tandf/tcim Email:ijcim@bath.ac.uk 


\section{Figures}

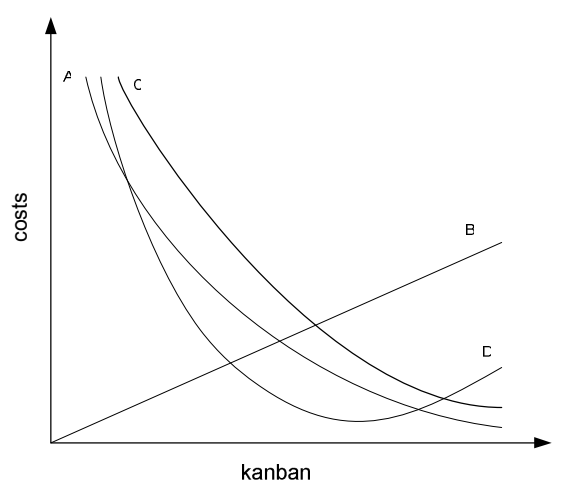

Figure 1 - Costs tendency based on the kanban number

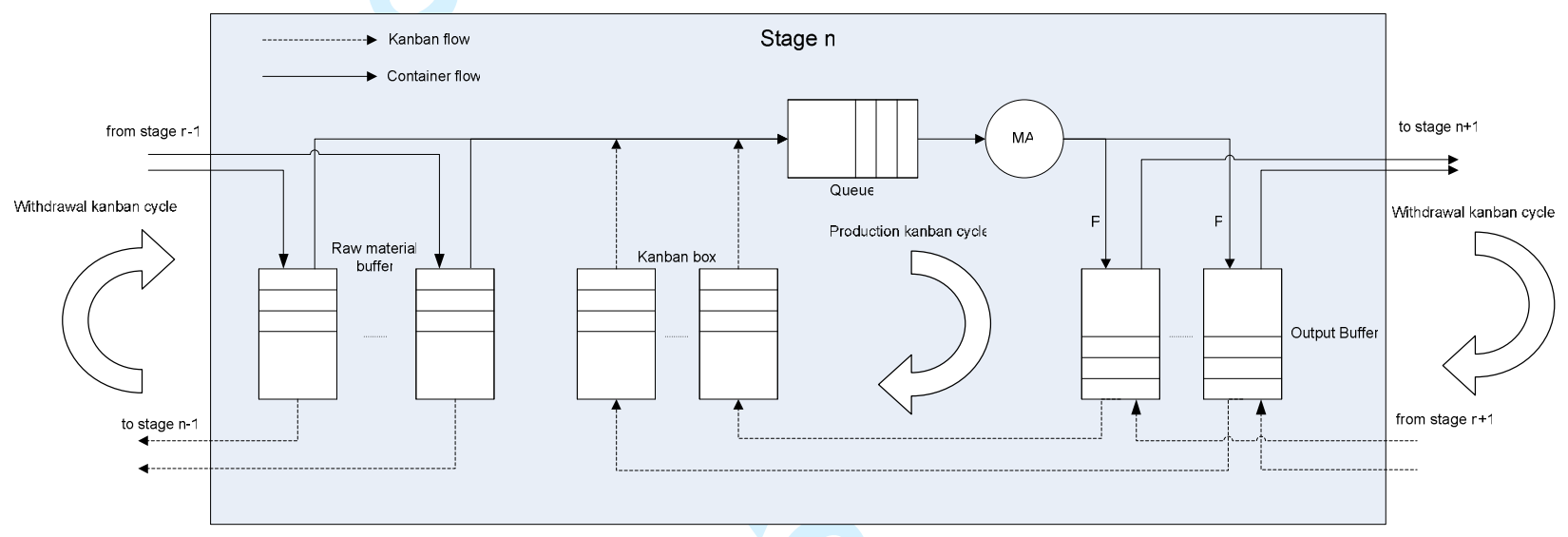

Figure 2 - Flow of kanbans and containers in a single stage
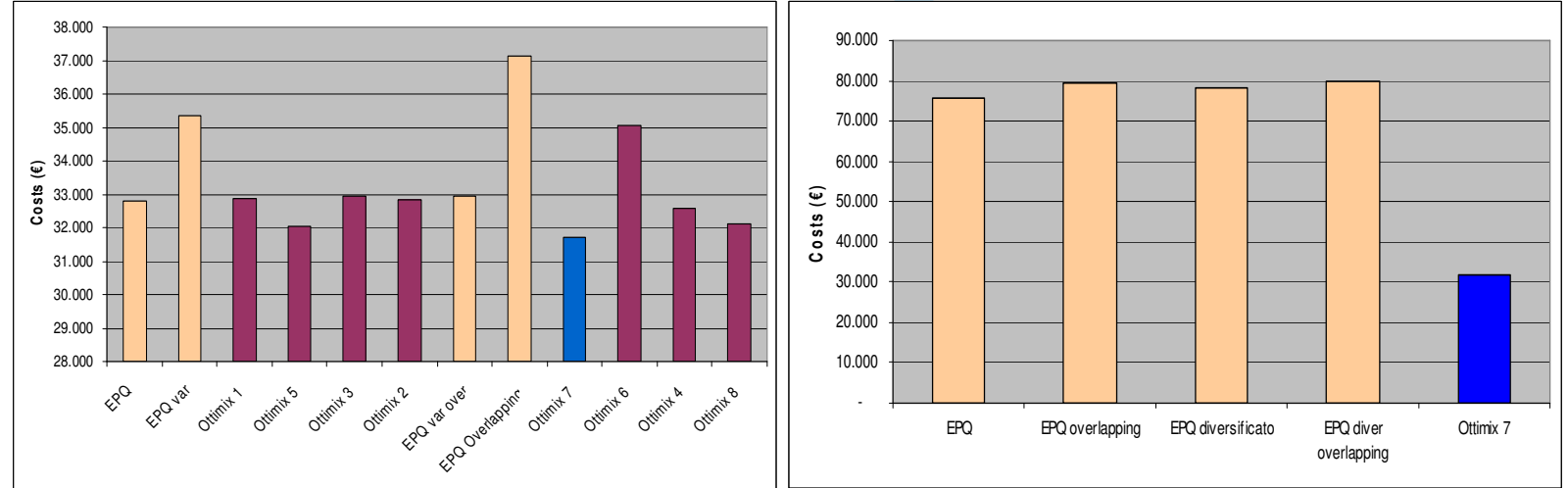

Figure 3 - Comparison between total costs (€) for "Time Periodic" (a) and "Quantity Periodic" (b) scenarios
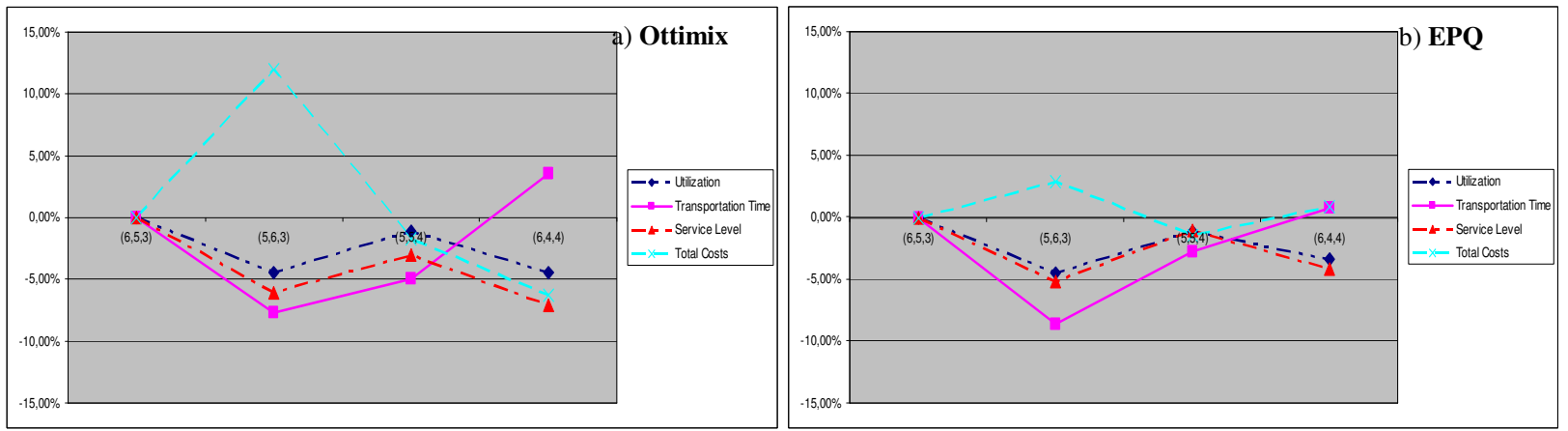
Figure 4-Gap analysis of the mix of demand
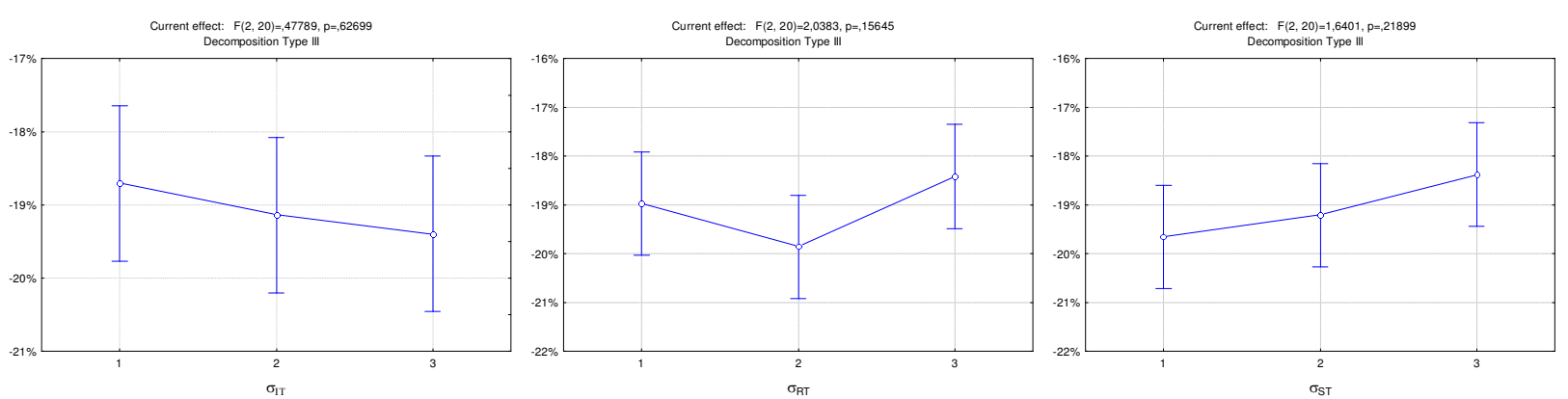

Figure 5 - Effect of factors in scenario 1
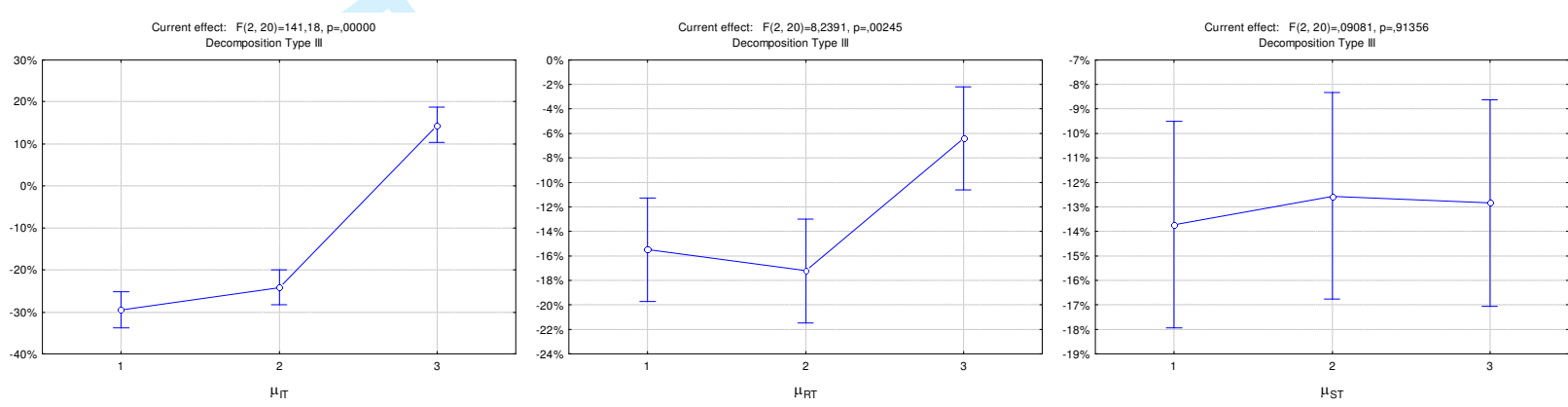

Figure 6- Effect of factors in scenario 2
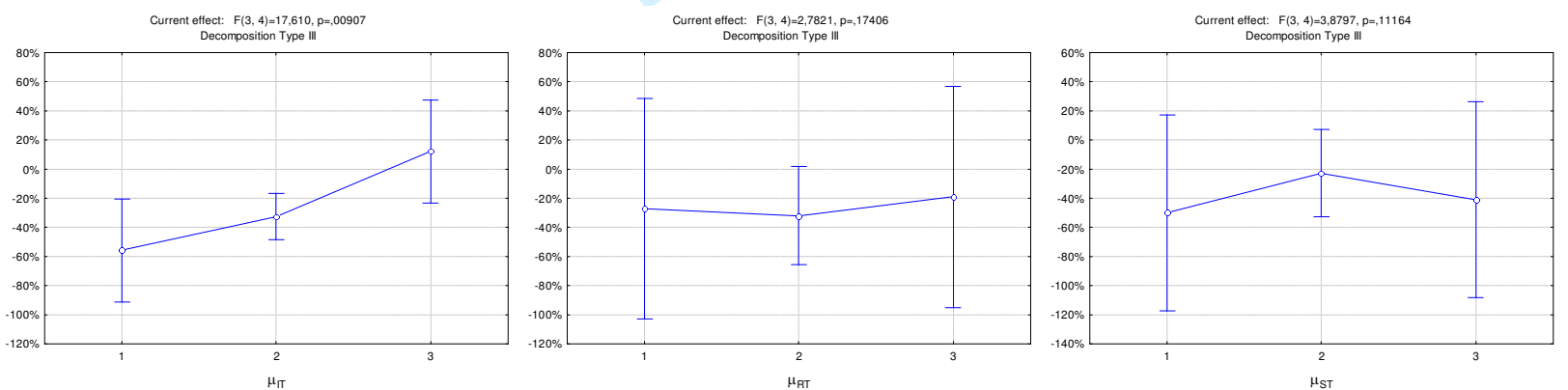

Figure 7- Effect of factors in scenario 3 


\section{Tables}

Table 1 - Production system parameters

\begin{tabular}{|c|c|c|c|c|c|c|}
\hline & Cell 1 & Cell 2 & Cell 3 & Cell 4 & Cell 5 & Cell 6 \\
\hline No. of Items & 3 & 2 & 1 & 1 & 2 & 2 \\
\hline Raw materials & 4 & 4 & 0 & 0 & 0 & 0 \\
\hline Run time & $\operatorname{TRIA}(3.0,3.8,5.0)$ & TRIA(2.0,3.0,5.0) & $\operatorname{TRIA}(3.0,3.5,4.5)$ & $\operatorname{TRIA}(4.0,4.5,6.0)$ & $\operatorname{TRIA}(3.0,4.0,4.5)$ & $\operatorname{TRIA}(3.0,4.0,4.5)$ \\
\hline Setup time & 0 & TRIA(2.2,3.0,4.0) & 0 & 0 & $\operatorname{TRIA}(1.5,2.0,3.4)$ & $\operatorname{TRIA}(1.5,2.0,3.4)$ \\
\hline Transport. Time & - & $\operatorname{Norm}(4.8,1.0)$ & $\operatorname{Norm}(4.8,1.0)$ & $\operatorname{Norm}(6.0,1.8)$ & $\operatorname{Norm}(7.2,2.0)$ & $\operatorname{Norm}(7.0,2.0)$ \\
\hline
\end{tabular}

Table 2 - Production kanban allocation for "Time Periodic" scenarios

\begin{tabular}{llll} 
Scenario & Production kanban & Scenario & Production kanban \\
\hline EPQ & $\Gamma_{E P Q}=(0,0,0,41,33,1,1,78,58,69,53)$ & Ottimix 3 & $\Gamma_{\text {Ottimix } 3}=(0,0,0,68,38,1,1,141,78,123,68)$ \\
EPQ var & $\Gamma_{E P Q \text { var }}=(0,0,0,50,28,1,1,87,48,78,43)$ & Ottimix 4 & $\Gamma_{\text {Ottimix } 4}=(0,0,0,68,38,1,1,141,78,132,73)$ \\
EPQ over & $\Gamma_{E P Q \text { Qver }}=(0,0,0,68,43,1,1,132,78,123,73)$ & Ottimix 5 & $\Gamma_{\text {Ottimix } 5}=(0,0,0,68,38,1,1,141,78,123,68)$ \\
EPQ var over & $\Gamma_{E P Q \text { varover }}=(0,0,0,68,38,1,1,141,78,123,68)$ & Ottimix 6 & $\Gamma_{\text {Ottimix } 6}=(0,0,0,77,43,1,1,132,73,132,73)$ \\
Ottimix 1 & $\Gamma_{\text {Ottimix } 1}=(0,0,0,68,38,1,1,132,73,123,68)$ & Ottimix 7 & $\Gamma_{\text {Ottimix } 7}=(0,0,0,77,43,1,1,141,78,123,68)$ \\
Ottimix 2 & $\Gamma_{\text {Ottimix } 2}=(0,0,0,68,38,1,1,132,73,132,73)$ & Ottimix 8 & $\Gamma_{\text {Ottimix } 8}=(0,0,0,77,43,1,1,141,78,132,73)$
\end{tabular}

Table 3 - Production kanban allocation for "Quantity Periodic" scenarios

\begin{tabular}{llll} 
Scenario & Production kanban & Scenario & Production kanban \\
\hline EPQ & $\Gamma_{E P Q}=(0,0,0,37,30,1,1,71,58,64,52)$ & EPQ var over & $\Gamma_{E P Q \text { var over }}=(0,0,0,68,38,1,1,141,78,126,70)$ \\
EPQ var & $\Gamma_{E P Q \text { var }}=(0,0,0,43,24,1,1,83,46,74,41)$ & Ottimix 7 & $\Gamma_{\text {Ottimix }}=(0,0,0,77,43,1,1,141,78,123,68)$ \\
EPQ over & $\Gamma_{E P Q \text { over }}=(0,0,0,65,40,1,1,137,81,123,72)$ & &
\end{tabular}

Table 4 - Matrix of factors for scenario 1

\begin{tabular}{cccc}
\hline & \multicolumn{3}{c}{ Level } \\
\hline Factor & 1 & 2 & 3 \\
$\boldsymbol{\sigma}_{\mathrm{IT}}$ & std & $+10 \%$ & $+20 \%$ \\
$\boldsymbol{\sigma}_{\mathrm{RT}}$ & std & $+10 \%$ & $+20 \%$ \\
$\boldsymbol{\sigma}_{\mathrm{ST}}$ & std & $+10 \%$ & $+20 \%$ \\
\hline
\end{tabular}

Table 5 - Results of the Main Effect ANOVA applied to the scenario 1

\begin{tabular}{c|ccccc} 
Effect & SS & DoF & MS & F & p \\
\hline$\sigma_{\text {IT }}$ & 0,000222 & 2 & 0,000111 & 0,477885 & 0,626994 \\
$\sigma_{\text {RT }}$ & 0,000948 & 2 & 0,000474 & 2,038251 & 0,156447 \\
$\sigma_{\text {ST }}$ & 0,000763 & 2 & 0,000381 & 1,640099 & 0,218995 \\
Error & 0,004652 & 20 & 0,000233 & &
\end{tabular}

Table 6 - Matrix of factors for scenario 2 and 3

\begin{tabular}{cccc}
\hline & \multicolumn{3}{c}{ Level } \\
\hline Factor & 1 & 2 & 3 \\
$\mu_{\mathrm{IT}}$ & $-10 \%$ & std & $+10 \%$ \\
$\mu_{\mathrm{RT}}$ & $-10 \%$ & std & $+10 \%$ \\
\hline
\end{tabular}




\begin{tabular}{llll}
\hline$\mu_{\mathrm{ST}}$ & $-10 \%$ & std & $+10 \%$ \\
\hline
\end{tabular}

Table 7 - Results of the Main Effect ANOVA applied to the scenario 2

\begin{tabular}{c|ccccc} 
Effect & SS & DoF & MS & F & p \\
\hline$\mu_{\text {IT }}$ & 1,039576 & 2 & 0,519788 & 141,1761 & 0,000000 \\
$\mu_{\text {RT }}$ & 0,060670 & 2 & 0,030335 & 8,2391 & 0,002455 \\
$\mu_{\text {ST }}$ & 0,000669 & 2 & 0,000334 & 0,0908 & 0,913565 \\
Error & 0,073637 & 20 & 0,003682 & &
\end{tabular}

Table 8 - Results of the One-Way ANOVA applied to the scenario 3

\begin{tabular}{c|ccccc} 
Effect & SS & DoF & MS & F & p \\
\hline$\mu_{\text {IT }}$ & 0,853325 & 3 & 0,284442 & 17,60982 & 0,009068 \\
Error & 0,064610 & 4 & 0,016152 & &
\end{tabular}

\begin{tabular}{c|ccccc} 
Effect & SS & DoF & MS & F & p \\
\hline$\mu_{\text {RT }}$ & 0,620536 & 3 & 0,206845 & 2,782064 & 0,174065 \\
Error & 0,297399 & 4 & 0,074350 & &
\end{tabular}

\begin{tabular}{c|ccccc} 
Effect & SS & DoF & MS & F & p \\
\hline$\mu_{\text {ST }}$ & 0,683154 & 3 & 0,227718 & 3,879682 & 0,111641 \\
Error & 0,234780 & 4 & 0,058695 & &
\end{tabular}

